\title{
Health outcomes associated with emergency department visits by adolescents for self-harm: a propensity-matched cohort study
}

\author{
William Gardner PhD, Kathleen Pajer MD MPH, Paula Cloutier MA, Lisa Currie MS, Ian Colman PhD, \\ Roger Zemek MD, Simon Hatcher MD, Isac Lima PhD, Mario Cappelli PhD
}

Cite as: CMAJ 2019 November 4;191:E1207-16. doi: 10.1503/cmaj.190188

Visual abstract available at www.cmaj.ca/lookup/suppl/doi:10.1503/cmaj.190188/-/DC2

\begin{abstract}
BACKGROUND: Self-harm is increasing among adolescents, and because of changing behaviours, current data are needed on the consequences of selfharm. We sought to investigate the trends related to hospital presentation, readmission, patient outcome and medical costs in adolescents who presented with self-harm to the emergency department.
\end{abstract}

METHODS: We used administrative data on 403805 adolescents aged $13-17$ years presenting to Ontario emergency departments in 2011-2013. Adolescents with self-harm visits were 1:2 propensity matched to controls with visits without self-harm, using demographic, mental health and other clinical variables. Five years after the index presentation, hospital or emergency department admission rates for self-harm, overall mortality, suicides and conservative cost estimates were compared between the 2 groups.

RESULTS: Of 5832 adolescents who visited Ontario emergency departments in 2011-2013 after self-harm (1.4\% of visits), 5661 were matched to 10731 adolescents who presented for reasons other than self-harm. Adolescents who presented with self-harm had a shorter time to a repeat emergency department or hospital admission for self-harm (hazard ratio [HR] $4.84,95 \%$ confidence interval $[\mathrm{Cl}]$ 4.44-5.27), more suicides (HR 7.96,
95\% Cl 4.00-15.86), and higher overall mortality (HR 3.23, 95\% Cl 2.12-4.93; $p<0.001)$. The positive predictive value of self-harm-related emergency department visits for suicide was $0.7 \%$. Adolescents with self-harm visits had mean 5-year estimates of health care costs of $\$ 30388$ compared with $\$ 19055$ for controls $(p<0.001)$.

INTERPRETATION: Adolescents with emergency department visits for selfharm have higher rates of mortality, suicide and recurrent self-harm, as well as higher health care costs, than matched controls. Development of algorithms and interventions that can identify and help adolescents at highest risk of recurrent self-harm is warranted.

\footnotetext{
(1)
}

ntentional self-harm is the deliberate act of injuring oneself, including attempts at suicide and nonsuicidal self-injury. ${ }^{1}$ Some of the consequences associated with adolescent selfharm are increased risk of death, ${ }^{2}$ including suicide; ${ }^{3-7}$ risk of injury owing to violence; ${ }^{8}$ and risks of mental health and substance abuse disorders, ${ }^{3,6,9-12}$ as well as other adverse psychosocial outcomes. ${ }^{13}$ Although several groups have carried out population-based studies of adolescents ${ }^{2,4,12}$ and reported that adolescents with emergency department visits for self-harm have worse outcomes than those with emergency department visits for other reasons, these studies controlled for only a limited number of covariates. Only 1 study ${ }^{14}$ reported data on the health care costs associated with adolescent self-harm. Emer- gency department visits by adolescents for self-harm in Ontario have more than doubled since $2009 .{ }^{15}$ Given adolescents' changing environments and influences (e.g., pervasive social media ${ }^{16}$ ) newer data are needed.

We carried out a population-based study comparing adolescents who presented to the emergency department after selfharm with adolescents who presented for reasons other than self-harm, using a propensity-matching design that controlled for a large number of demographic, mental health and other clinical variables. The primary objective of this study was to test the hypothesis that adolescents presenting to emergency departments after self-harm would have higher 5-year rates of emergency department and hospital readmissions for self-harm, 
suicide and overall mortality than adolescents presenting to emergency departments for other reasons. We also hypothesized that adolescents presenting with self-harm would incur more costly medical care over 5 years than those not presenting with self-harm. The secondary objective was to identify demographic, health-related and social predictors of poor outcomes within the self-harm group.

\section{Methods}

\section{Study design, setting and participants}

This is a prospective cohort study of adolescents aged 13 to 17 years (inclusive) who presented to Ontario emergency departments from Jan. 1, 2011, through Dec. 31, 2013, with an Ontario Health Insurance Plan number and were discharged alive. Adolescents with emergency department visits for selfharm were propensity matched to control adolescent patients, using demographic and clinical variables. The self-harm group included adolescents with at least 1 emergency department visit with an International Classification of Diseases, 10th Revision (ICD-10) self-harm code. ${ }^{17}$ The control group comprised all other adolescents with emergency department visits for other reasons. Participants were followed from the date of the index emergency department visit until death, or 5 years after the index visit.

\section{Data sources}

The National Ambulatory Care Reporting System was the source of data on emergency department visits. We used the Discharge Abstract Database to identify acute care hospital admissions with a self-harm code, as well as specific health care conditions and comorbidities. We used data from the Ontario Health Insurance Plan and the Ontario Mental Health Reporting System to identify patients' health care conditions 1 year before the emergency department visits. The quality of National Ambulatory Care Reporting System data within several Ontario emergency departments has been determined to be good, with agreement rates for ICD-10 codes ranging from $86 \%$ to $90 \% .{ }^{18}$ We identified sociodemographic characteristics using the Registered Person Database. Finally, we identified decedents through the Office of the Registrar General of Ontario Death Database. These data sets were linked using unique encoded identifiers and analyzed at ICES. ICES is an independent, nonprofit research institute whose legal status under Ontario's health information privacy law allows it to collect and analyze health care and demographic data, without consent, for health system evaluation and improvement.

\section{Measurements}

\section{Self-harm}

Self-harm emergency department visits and hospital admissions were defined as events with ICD-10 codes X6, X7 or X80-X84. We combined self-injury and self-poisoning into a single self-harm variable.

When an adolescent visited the emergency department more than once in 2011-2013, we selected the index visit as follows: if none of the adolescent's visits were related to self-harm, we selected the first visit; if 1 visit was related to self-harm, we selected that visit; if there were multiple visits related to selfharm, we selected the first.

\section{Outcomes}

\section{Suicides and overall mortality}

We identified suicides and deaths from all causes (overall mortality). We determined suicides using a validated method developed by ICES using ICD9 codes E950-E959 or ICD10 codes X6084. ${ }^{19}$ This method has $\geq 95 \%$ sensitivity for the period under study.

\section{Repeat self-harm emergency department visits or hospital admission}

We searched the National Ambulatory Care Reporting System and Discharge Abstract Database for the 5 years after the index visit to find records of emergency department visits or hospital admissions with self-harm codes.

\section{Estimates of medical costs}

We calculated the cumulative 5-year cost of all health services captured in ICES - i.e., not just those attributable to selfharm - using a standard ICES macro. ${ }^{20}$ These services included inpatient hospital admissions (both acute and psychiatric), physician-related visits and laboratory tests, emergency department visits and other ambulatory care, outpatient prescription drugs (for adolescents covered only under the Ontario Drug Benefit program, which is designed for indigent patients), rehabilitation, home care, complex continuing care, long-term care and assisted devices. The cost estimates do not include outpatient drug costs (except for families receiving public assistance), nonphysician services, out-of-pocket costs of care or services covered by private insurance, including the costs of most care provided by psychologists and social workers, and all care by mental health nurses in schools. Therefore, these estimates are lower bounds on the actual 5-year health care costs incurred by patients.

\section{Covariates of self-harm}

The covariates we used in matching included sex, age, residence and income quintile of the Canadian Census Dissemination Area of residence. They also included clinical covariates found in the National Ambulatory Care Reporting System, Discharge Abstract Database, Ontario Health Insurance Plan and Ontario Mental Health Reporting System databases (Appendix 1, available at www.cmaj.ca/lookup/suppl/doi:10.1503/ cmaj.190188/-/DC1). The clinical covariates included mental health and substance misuse diagnostic codes, and a set of non-mental health diagnoses that had been included in a comprehensive epidemiologic study of the covariates of adult selfharm. ${ }^{21}$ These clinical covariates could have been recorded for the index visit or any other health care interaction during the year before that visit. Finally, the covariates used in the propensity score included self-harm codes occurring during the prior 
year. This means that self-harm that occurred in the year before the emergency department visit was used to propensity-match adolescents with self-harm visits to controls patients. Because of how we selected patients, only those adolescents with emergency department visits in 2011 could have had visits related to self-harm in the prior year.

\section{Statistical analysis}

We used propensity scores to match adolescents with visits related to self-harm to control patients. We carried out a logistic regression to estimate the probability of an emergency department visit related to self-harm (PSCORE) from the covariates listed in Appendix 1. Next, we excluded participants whose PSCORE fell outside the common support interval:

common support $=[\min ($ PSCORE in self-harm group), $\max (P S C O R E$ in no-self-harm group)].

The common support interval is the range of propensity scores in which the participants in the self-harm and control groups were comparable. ${ }^{22}$ For example, an adolescent in the self-harm group with a propensity score of self-harm that is higher than that of any adolescent in the control group has no meaningful propensity score match among the controls. We then sought 2 matched controls for each of the adolescents with visits related to self-harm (case). ${ }^{22-24}$ Cases were matched to the same age, sex and rurality as the control patient who was closest on the PSCORE (Appendix 1). Finally, we assessed whether the matched adolescents with and without emergency department visits related to self-harm were balanced on our covariates using the standardized mean difference $(D)$,

$D=[$ mean (covariate in self-harm group) - mean(covariate in noself-harm group)]/SD

where SD is the average of the standard deviations for the selfharm and no-self-harm groups. We used stratified Cox proportional hazards regression to compare adolescents with visits related to self-harm to control patients on the time from the index visit to death from any cause. We analyzed time to suicide data similarly, but with death from other causes as a competing risk. We analyzed time from the index visit to an emergency department or hospital readmission for self-harm with death by any cause as a competing risk. We log-transformed lower-bound cost estimates and compared them using paired $t$-tests. In addition, we placed patients into 4 groups defined by self-harm visit (yes v. no) and mental health visit (yes v. no) and used a $2 \times 2$ analysis of variance to compare the log-transformed lowerbound cost estimates. The analyses used SAS version 9.3 (SAS Institute, Cary, North Carolina). Finally, for the outcomes of readmission, mortality and suicide, we calculated the relative risk (RR) and positive predictive value (PPV) associated with selfharm, where

$P P V=\operatorname{Pr}$ (outcome|self-harm) and $R R=\operatorname{Pr}$ (outcome|self-harm) $/$ $\operatorname{Pr}$ (outcome|no self-harm).

\section{Ethics approval}

Approval to complete this study was granted by the Children's Hospital of Eastern Ontario Research Ethics Board.

\section{Results}

\section{Study cohort}

There were 407647 adolescents who visited an emergency department in Ontario from Jan. 1, 2011, to Dec. 31, 2013. We excluded 569 adolescents $(0.1 \%)$ because they were not covered by the Ontario Health Insurance Plan. After calculating the propensity scores, we excluded an additional $3273(0.8 \%)$ because they fell outside the common support interval. The resulting 403805 adolescents comprised the unmatched cohort, as shown in Table 1 . The 5832 adolescents with $\geq 1$ visits related to self-harm (1.4\%) were older, more likely to be female and less likely to reside in a rural community than those with 0 visits related to self-harm. Adolescents with visits related to self-harm had higher rates on every mental health or substance abuse variable. Group differences $(D)$ for the mental health and selfharm variables were in the range $0.09 \leq D \leq 1.14$, with the largest difference being for anxiety-neurotic disorders. Group differences for non-mental health clinical variables ranged from 0.0 to 0.19 , with the greatest difference for concussion-traumatic brain injury $\left(D=0.20\right.$ is commonly viewed as a small effect size $\left.{ }^{25}\right)$.

We found matches for 5661 (97.1\%) of the adolescents with visits related to self-harm. The 1:2 matching strategy produced 10731 controls. The resulting groups were balanced on all covariates except suicidal ideation $(D=0.17)$.

\section{Propensity-matched comparisons of outcomes}

Table 2 presents the study outcomes for youths with emergency department visits related to self-harm and those visits unrelated to self-harm in both the unmatched and the matched cohorts. Table 3 reports the time-to-event analyses for self-harm readmissions, overall mortality and suicides. For each outcome, adolescents with $\geq 1$ visits related to self-harm were likely to have the outcome sooner than matched adolescents with no self-harm visits. Adolescents with visits related to self-harm were more likely to have a subsequent hospital admission or emergency department visit for self-harm within 5 years (RR 4.84, 95\% confidence interval $[\mathrm{Cl}]$ 4.44-5.27). The positive predictive values of a visit related to self-harm were $\leq 1 \%$ for mortality or suicide, whereas that for readmission with self-harm was $28.7 \%$. Figure 1 presents Kaplan-Meier estimates of the time to first repeat emergency department visit or hospital admission for self-harm in the matched cohort. Finally, adolescents with a self-harm visit had $\$ 11333$ greater mean of 5-year cost estimates (lower bound) than the matched controls.

\section{Self-harm, history of mental health conditions and outcomes}

Table 1 shows that most adolescents with visits related to selfharm also have a history of use of mental health services, including $62 \%$ having used services owing to anxiety-neurotic disorders. This prompted the question of whether self-harm or 
Table 1 (part 1 of 2): Demographic, mental health and clinical covariates of emergency department visits for self-harm*

\begin{tabular}{|c|c|c|c|c|c|c|c|c|}
\hline & & Unmatched c & hort & & & Matched & hort & \\
\hline Variable & $\begin{array}{c}\text { No. }(\%) \dagger \text { of } \\
\text { adolescents } \\
\text { with no } \\
\text { self-harm } \\
\text { visits } \\
n=397973\end{array}$ & $\begin{array}{c}\text { No. }(\%) \dagger \text { of } \\
\text { adolescents } \\
\text { with } \geq 1 \\
\text { self-harm } \\
\text { visits } \\
n=5832\end{array}$ & $\begin{array}{l}\text { Total } \\
n=\mathbf{4 0 3 8 0 5}\end{array}$ & D & $\begin{array}{l}\text { No. }(\%) \dagger \text { of } \\
\text { adolescents } \\
\text { with no } \\
\text { self-harm } \\
\text { visits } \\
n=10731\end{array}$ & $\begin{array}{c}\text { No. }(\%) \dagger \text { of } \\
\text { adolescents } \\
\text { with } \geq 1 \\
\text { self-harm } \\
\text { visits } \\
n=5661\end{array}$ & $\begin{array}{c}\text { Total } \\
n=16392\end{array}$ & D \\
\hline Demographic covariates & & & & & & & & \\
\hline Age, $y r$, mean $\pm S D$ & $14.95 \pm 1.46$ & $15.47 \pm 1.26$ & $14.96 \pm 1.46$ & 0.38 & $15.47 \pm 1.27$ & $15.48 \pm 1.26$ & $15.48 \pm 1.27$ & 0.00 \\
\hline Sex, female & $188947(47.5)$ & $4602(78.9)$ & $193549(47.9)$ & 0.69 & $8345(77.8)$ & $4444(78.5)$ & $12789(78.0)$ & 0.02 \\
\hline Neighbourhood income quintile & & & & & & & & \\
\hline 1 & $71924(18.1)$ & $1265(21.7)$ & $73189(18.1)$ & 0.09 & $2385(22.2)$ & $1225(21.6)$ & $3610(22.0)$ & 0.01 \\
\hline 2 & $73747(18.5)$ & $1091(18.7)$ & $74838(18.5)$ & 0.00 & $2028(18.9)$ & $1061(18.7)$ & $3089(18.8)$ & 0.00 \\
\hline 3 & $80365(20.2)$ & $1183(20.3)$ & $81548(20.2)$ & 0.00 & $2169(20.2)$ & $1149(20.3)$ & $3318(20.2)$ & 0.00 \\
\hline 4 & $87268(21.9)$ & $1197(20.5)$ & $88465(21.9)$ & 0.03 & $2175(20.3)$ & $1163(20.5)$ & $3338(20.4)$ & 0.01 \\
\hline 5 & $84669(21.3)$ & $1096(18.8)$ & $85765(21.2)$ & 0.06 & $1974(18.4)$ & $1063(18.8)$ & $3037(18.5)$ & 0.01 \\
\hline Rural & $69467(17.5)$ & $906(15.5)$ & $70373(17.4)$ & 0.05 & $1556(14.5)$ & $887(15.7)$ & $2443(14.9)$ & 0.03 \\
\hline Mental health and substance abuse cove & iates & & & & & & & \\
\hline Alcohol abuse & $2564(0.6)$ & $463(7.9)$ & $3027(0.7)$ & 0.37 & $661(6.2)$ & $413(7.3)$ & $1074(6.6)$ & 0.05 \\
\hline Anxiety-neurotic disorders & $55540(14.0)$ & $3625(62.2)$ & $59165(14.7)$ & 1.14 & $6434(60.0)$ & $3454(61.0)$ & $9888(60.3)$ & 0.02 \\
\hline Behavioural and emotional disorders & $51188(12.9)$ & $2073(35.5)$ & $53261(13.2)$ & 0.55 & 3715 (34.6) & $1941(34.3)$ & $5656(34.5)$ & 0.01 \\
\hline $\begin{array}{l}\text { Behavioural syndromes associated with } \\
\text { physiologic disturbances }\end{array}$ & $884(0.2)$ & $52(0.9)$ & $936(0.2)$ & 0.09 & $80(0.7)$ & $49(0.9)$ & $129(0.8)$ & 0.01 \\
\hline Bipolar disorder or manic episode & $2953(0.7)$ & $754(12.9)$ & $3707(0.9)$ & 0.50 & $1005(9.4)$ & $664(11.7)$ & $1669(10.2)$ & 0.08 \\
\hline Disorders of personality and behaviour & $2170(0.5)$ & $523(9.0)$ & $2693(0.7)$ & 0.40 & $583(5.4)$ & $446(7.9)$ & $1029(6.3)$ & 0.10 \\
\hline Disorders of psychological development & $8678(2.2)$ & $388(6.7)$ & $9066(2.2)$ & 0.22 & $593(5.5)$ & $355(6.3)$ & $948(5.8)$ & 0.03 \\
\hline Eating disorders & $410(0.1)$ & $216(3.7)$ & $626(0.2)$ & 0.27 & $198(1.8)$ & $166(2.9)$ & $364(2.2)$ & 0.07 \\
\hline Intellectual disability & $978(0.2)$ & $46(0.8)$ & $1024(0.3)$ & 0.08 & $63(0.6)$ & $37(0.7)$ & $100(0.6)$ & 0.01 \\
\hline $\begin{array}{l}\text { Mood disorders other than bipolar or } \\
\text { mania }\end{array}$ & $12101(3.0)$ & $2353(40.3)$ & $14454(3.6)$ & 1.02 & $3968(37.0)$ & $2183(38.6)$ & $6151(37.5)$ & 0.03 \\
\hline Organic mental disorders & $639(0.2)$ & $48(0.8)$ & $687(0.2)$ & 0.09 & $79(0.7)$ & $42(0.7)$ & $121(0.7)$ & 0.00 \\
\hline Other mental health disorders & $149(0.0)$ & $57(1.0)$ & $206(0.1)$ & 0.13 & $51(0.5)$ & $48(0.8)$ & $99(0.6)$ & 0.05 \\
\hline $\begin{array}{l}\text { Reaction to severe stress, and } \\
\text { adjustment disorders }\end{array}$ & $8500(2.1)$ & $1537(26.4)$ & $10037(2.5)$ & 0.74 & $2402(22.4)$ & $1383(24.4)$ & $3785(23.1)$ & 0.05 \\
\hline Schizophrenia & $1636(0.4)$ & $282(4.8)$ & $1918(0.5)$ & 0.28 & $415(3.9)$ & $239(4.2)$ & $654(4.0)$ & 0.02 \\
\hline Substance abuse (non-alcohol) & $3906(1.0)$ & $615(10.5)$ & $4521(1.1)$ & 0.42 & $860(8.0)$ & $550(9.7)$ & $1410(8.6)$ & 0.06 \\
\hline Suicidal ideation & $1807(0.5)$ & $1134(19.4)$ & $2941(0.7)$ & 0.67 & $1195(11.1)$ & $969(17.1)$ & $2164(13.2)$ & 0.17 \\
\hline Clinical covariates & & & & & & & & \\
\hline Acne & $45793(11.5)$ & $805(13.8)$ & $46598(11.5)$ & 0.07 & $1447(13.5)$ & $785(13.9)$ & $2232(13.6)$ & 0.01 \\
\hline Asthma & $50800(12.8)$ & $837(14.4)$ & $51637(12.8)$ & 0.05 & $1484(13.8)$ & $797(14.1)$ & $2281(13.9)$ & 0.01 \\
\hline Cancers & $2054(0.5)$ & $34(0.6)$ & $2088(0.5)$ & 0.01 & $48(0.4)$ & $33(0.6)$ & $81(0.5)$ & 0.02 \\
\hline Concussion or traumatic brain injury & $60069(15.1)$ & $1302(22.3)$ & $61371(15.2)$ & 0.19 & $2243(20.9)$ & $1234(21.8)$ & $3477(21.2)$ & 0.02 \\
\hline Congenital heart disease & $2906(0.7)$ & $34(0.6)$ & $2940(0.7)$ & 0.02 & $70(0.7)$ & $34(0.6)$ & $104(0.6)$ & 0.01 \\
\hline Cystic fibrosis & $117(0.0)$ & $\leq 5$ & $120(0.0)$ & 0.01 & $\leq 5$ & $\leq 5$ & $6(0.0)$ & 0.01 \\
\hline Diabetes mellitus & $4121(1.0)$ & $87(1.5)$ & $4208(1.0)$ & 0.04 & $134(1.2)$ & $84(1.5)$ & $218(1.3)$ & 0.02 \\
\hline Down syndrome & $1268(0.3)$ & $14(0.2)$ & $1282(0.3)$ & 0.01 & $29(0.3)$ & $14(0.2)$ & $43(0.3)$ & 0.00 \\
\hline Eczema & $80290(20.2)$ & $1345(23.1)$ & $81635(20.2)$ & 0.07 & $2318(21.6)$ & $1286(22.7)$ & $3604(22.0)$ & 0.03 \\
\hline Epilepsy & $4649(1.2)$ & $117(2.0)$ & $4766(1.2)$ & 0.07 & $189(1.8)$ & $107(1.9)$ & $296(1.8)$ & 0.01 \\
\hline
\end{tabular}




\begin{tabular}{|c|c|c|c|c|c|c|c|c|}
\hline \multirow[b]{2}{*}{ Variable } & \multicolumn{4}{|c|}{ Unmatched cohort } & \multicolumn{4}{|c|}{ Matched cohort } \\
\hline & $\begin{array}{l}\text { No. }(\%) \dagger \text { of } \\
\text { adolescents } \\
\text { with no } \\
\text { self-harm } \\
\text { visits } \\
n=397973\end{array}$ & $\begin{array}{l}\text { No. }(\%) \dagger \text { of } \\
\text { adolescents } \\
\text { with } \geq 1 \\
\text { self-harm } \\
\text { visits } \\
n=5832\end{array}$ & $\begin{array}{c}\text { Total } \\
n=\mathbf{4 0 3 8 0 5}\end{array}$ & D & $\begin{array}{c}\text { No. }(\%) \dagger \text { of } \\
\text { adolescents } \\
\text { with no } \\
\text { self-harm } \\
\text { visits } \\
n=10731\end{array}$ & $\begin{array}{c}\text { No. }(\%) \dagger \text { of } \\
\text { adolescents } \\
\text { with } \geq 1 \\
\text { self-harm } \\
\text { visits } \\
n=5661\end{array}$ & $\begin{array}{c}\text { Total } \\
n=16392\end{array}$ & D \\
\hline Inflammatory polyarthropathies & $2156(0.5)$ & $36(0.6)$ & $2192(0.5)$ & 0.01 & $62(0.6)$ & $33(0.6)$ & $95(0.6)$ & 0.00 \\
\hline Migraine & $15306(3.8)$ & $419(7.2)$ & 15725 (3.9) & 0.15 & $732(6.8)$ & $400(7.1)$ & $1132(6.9)$ & 0.01 \\
\hline Neuromuscular conditions & $1477(0.4)$ & $14(0.2)$ & $1491(0.4)$ & 0.02 & $36(0.3)$ & $14(0.2)$ & $50(0.3)$ & 0.02 \\
\hline Obesity & $10340(2.6)$ & $209(3.6)$ & $10549(2.6)$ & 0.06 & $352(3.3)$ & $202(3.6)$ & $554(3.4)$ & 0.02 \\
\hline Psoriasis & $2361(0.6)$ & $36(0.6)$ & $2397(0.6)$ & 0.00 & $62(0.6)$ & $35(0.6)$ & $97(0.6)$ & 0.01 \\
\hline Sickle cell anemia & $607(0.2)$ & $6(0.1)$ & $613(0.2)$ & 0.01 & $8(0.1)$ & $6(0.1)$ & $14(0.1)$ & 0.01 \\
\hline Spina bifida & $286(0.1)$ & $\leq 5$ & $289(0.1)$ & 0.01 & $\leq 5$ & $\leq 5$ & $8(0.0)$ & 0.00 \\
\hline \multicolumn{9}{|l|}{ History of self-harm } \\
\hline Self-injury & $402(0.1)$ & $124(2.1)$ & $526(0.1)$ & 0.19 & $164(1.5)$ & $109(1.9)$ & $273(1.7)$ & 0.03 \\
\hline Self-poisoning & $778(0.2)$ & $260(4.5)$ & $1038(0.3)$ & 0.29 & $338(3.1)$ & $236(4.2)$ & $574(3.5)$ & 0.05 \\
\hline
\end{tabular}

\section{Table 2: Outcomes of emergency department visits*}

\begin{tabular}{|c|c|c|c|c|c|c|c|c|}
\hline \multirow[b]{2}{*}{ Outcome } & \multicolumn{4}{|c|}{ Unmatched cohort } & \multicolumn{4}{|c|}{ Matched cohort } \\
\hline & $\begin{array}{c}\text { No. }(\%) \dagger \text { of } \\
\text { adolescents } \\
\text { with no } \\
\text { self-harm } \\
\text { visits } \\
n=397973\end{array}$ & $\begin{array}{c}\text { No. }(\%) \dagger \text { of } \\
\text { adolescents } \\
\text { with } \geq 1 \\
\text { self-harm } \\
\text { visits } \\
n=5832\end{array}$ & $\begin{array}{c}\text { Total } \\
n=403805\end{array}$ & $D$ & $\begin{array}{l}\text { No. }(\%) \dagger \text { of } \\
\text { adolescents } \\
\text { with no self- } \\
\text { harm visits } \\
n=10731\end{array}$ & $\begin{array}{c}\text { No. }(\%) \dagger \text { of } \\
\text { adolescents } \\
\text { with } \geq 1 \\
\text { self-harm } \\
\text { visits } \\
n=5661\end{array}$ & $\begin{array}{c}\text { Total } \\
n=16392\end{array}$ & $D$ \\
\hline $\begin{array}{l}\text { Readmissions to emergency } \\
\text { department or hospital for self-harm }\end{array}$ & $7252(1.8)$ & $1718(29.5)$ & $8970(2.2)$ & 1.88 & $637(5.9)$ & $1626(28.7)$ & $2263(13.8)$ & 0.66 \\
\hline Suicides & $199(0.1)$ & $43(0.7)$ & $242(0.1)$ & 0.29 & $10(0.1)$ & $42(0.7)$ & $52(0.3)$ & 0.12 \\
\hline Deaths & $937(0.2)$ & $61(1.0)$ & $998(0.3)$ & 0.16 & $34(0.3)$ & $58(1.0)$ & $92(0.6)$ & 0.09 \\
\hline $\begin{array}{l}\text { Lower-bound estimates of 5-year health } \\
\text { care costs, mean } \pm \text { SD }\end{array}$ & $\begin{array}{l}9271 \pm \\
32829\end{array}$ & $\begin{array}{c}31698 \pm \\
64011\end{array}$ & $\begin{array}{l}9595 \pm \\
33593\end{array}$ & 0.44 & $\begin{array}{c}19055 \pm \\
53767\end{array}$ & $\begin{array}{c}30388 \pm \\
61312\end{array}$ & $\begin{array}{c}22969 \pm \\
56742\end{array}$ & 0.20 \\
\hline
\end{tabular}

Note: $D=$ standardized group difference, $\mathrm{SD}=$ standard deviation .

*In cells containing " $\leq 5$," the actual count and percentage were suppressed to prevent reidentification of patients.

†Unless stated otherwise.

a history of mental health conditions are predictors for worse 5 -year outcomes. Table 4 shows that 4655 (28.4\%) of adolescents in our matched comparison groups had a mental health code associated with the index emergency department visit or any other medical service in the last year (history of a mental health condition). The confidence intervals for hazard ratios (HRs) for self-harm were $>4$ for readmissions (HR $6.81,95 \% \mathrm{Cl}$ 6.08-7.64), overall mortality ( $\mathrm{HR} 4.26,95 \% \mathrm{Cl} 2.57-7.05)$, and suicides (HR 11.48, 95\% Cl 4.79-27.5). Having a history of a mental health condition was associated with a shorter time to readmission for self-harm ( $\mathrm{HR} 1.92, \mathrm{Cl} 1.65-2.24)$, but not for overall mortality (HR $1.38,95 \% \mathrm{Cl} 0.69-2.79$ ) or suicides (HR
$1.69,95 \% \mathrm{Cl} 0.48-5.98)$. We found that both self-harm ( $p<$ $0.001)$ and history of a mental health condition $(p<0.001)$ were associated with increased lower-bound costs. However, among those adolescents with visits related to self-harm, mental health history was not associated with increased lowerbound costs.

\section{Factors associated with readmission after emergency department visits related to self-harm}

Finally, we carried out an exploratory analysis to identify factors associated with readmissions to the hospital or emergency department within the cohort of 5661 adolescents with an 
Table 3: Association of self-harm with 5-year outcomes; propensity-matched comparisons*

\begin{tabular}{|c|c|c|c|c|c|c|}
\hline Outcome & $\begin{array}{c}\text { No. }(\%) \text { of } \\
\text { adolescents } \\
\text { with no } \\
\text { self-harm visits } \\
n=10731\end{array}$ & $\begin{array}{c}\text { No. }(\%) \text { of } \\
\text { adolescents } \\
\text { with } \geq 1 \\
\text { self-harm visits } \\
n=5661\end{array}$ & \multicolumn{2}{|c|}{$\begin{array}{l}\text { Time-to-event analyses } \\
\text { HR }(95 \% \mathrm{CI})\end{array}$} & RR $(95 \% \mathrm{Cl})$ & $\begin{array}{l}\text { Positive } \\
\text { predictive } \\
\text { value }\end{array}$ \\
\hline $\begin{array}{l}\text { Readmissions to emergency } \\
\text { department or hospital for self-harm }\end{array}$ & $637(5.9)$ & $1626(28.7)$ & \multicolumn{2}{|c|}{$5.52(5.05-6.04)$} & $4.84(4.44-5.27)$ & 28.7 \\
\hline Overall mortality & $34(0.3)$ & $58(1.0)$ & \multicolumn{2}{|c|}{$3.25(2.12-4.96)$} & $3.23(2.12-4.93)$ & 1.0 \\
\hline \multirow[t]{2}{*}{ Suicides } & $10(0.1)$ & $42(0.7)$ & \multicolumn{2}{|c|}{$8.00(3.99-16.04)$} & $7.96(4.00-15.86)$ & 0.7 \\
\hline & Mean \pm SD & Mean \pm SD & $t$ & $p$ value & \multicolumn{2}{|l|}{ D } \\
\hline $\begin{array}{l}\text { Lower-bound estimates of 5-year } \\
\text { health care costs, } \$\end{array}$ & $19055 \pm 53767$ & $30388 \pm 61312$ & 31.96 & $<0.001$ & 0.20 & N/A \\
\hline \multicolumn{7}{|c|}{$\begin{array}{l}\text { Note: } \mathrm{Cl}=\text { confidence interval, } D=\text { group difference, } \mathrm{HR}=\text { hazard ratio, } \mathrm{N} / \mathrm{A}=\text { not applicable, } \mathrm{RR}=\text { relative risk. } \\
\text { * Hazard ratio is from the Cox proportional regression (meaning, the hazard rate for adolescents with } \geq 1 \text { self-harm visits divided by the rate for the matched controls) for that outcome. } \\
\text { The positive predictive value is the proportion of youths with } \geq 1 \text { self-harm visits who have the outcome. Relative risk is the probability of the occurrence of the outcome within } 5 \text { years } \\
\text { for adolescents with } \geq 1 \text { self-harm visits divided by the probability of the outcome for the matched controls. } t \text { statistic is the comparison of the average log-transformed lower-bound } \\
\text { costs, with statistical significance } p \text {. }\end{array}$} \\
\hline
\end{tabular}

\section{Kaplan-Meier curve}

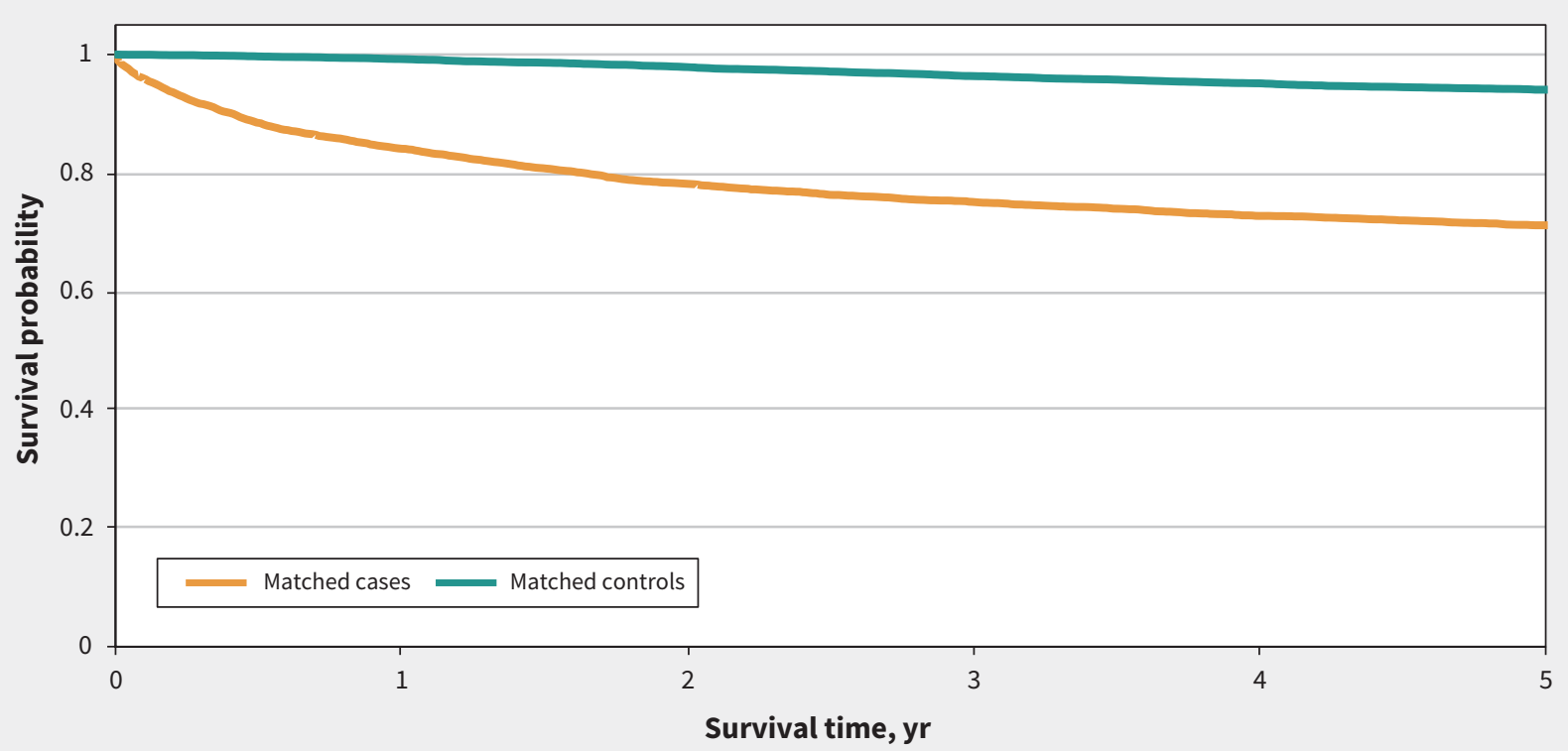

Figure 1: Time to next emergency department visit or hospital admission for self-harm among propensity-matched pairs.

emergency department visit for self-harm. Table 5 shows that adolescents with emergency department visits related to selfharm who were readmitted were more likely to be younger $(p<$ $0.001)$, female $(p<0.001)$ and to reside in a rural community $(p=0.002)$. They were more likely to have had a concussion or traumatic brain injury $(p=0.002)$ or epilepsy $(p<0.001)$, and less likely to have diabetes $(p<0.001)$. Readmitted adolescents were also more likely to have had a history of abusing alcohol $(p<$ 0.001 ) or other substances, to have a history of nearly every men- tal health concern and to have had a history of self-harm before the index emergency department visit $(p<0.001)$.

\section{Interpretation}

Over a 5-year follow-up of a cohort of adolescents who presented to emergency departments in Ontario, those whose visits were related to self-harm were more than 3 times more likely to die from any cause and almost 8 times more likely to die by 


\begin{tabular}{|c|c|c|c|c|c|c|c|}
\hline & \multicolumn{2}{|c|}{$\begin{array}{l}\text { No. of adolescents with } \\
\text { no history of mental health } \\
\text { conditions } \\
n=11737\end{array}$} & \multicolumn{2}{|c|}{$\begin{array}{l}\text { No. of adolescents with } \\
\text { history of mental health } \\
\text { conditions } \\
n=4655\end{array}$} & \multicolumn{3}{|c|}{ Time-to-event analyses } \\
\hline Outcome & $\begin{array}{c}\text { No. }(\%) \dagger \text { of } \\
\text { adolescents } \\
\text { with no } \\
\text { self-harm } \\
\text { visits } \\
n=7693\end{array}$ & $\begin{array}{c}\text { No. }(\%) \dagger \text { of } \\
\text { adolescents } \\
\text { with } \geq 1 \\
\text { self-harm } \\
\text { visits } \\
n=4044\end{array}$ & $\begin{array}{c}\text { No. }(\%) \dagger \text { of } \\
\text { adolescents } \\
\text { with no } \\
\text { self-harm } \\
\text { visits } \\
n=3038\end{array}$ & $\begin{array}{c}\text { No. }(\%) \dagger \text { of } \\
\text { adolescents } \\
\text { with } \geq 1 \\
\text { self-harm } \\
\text { visits } \\
n=1617\end{array}$ & $\begin{array}{c}\text { Self-harm } \\
\text { HR }(95 \% \mathrm{CI})\end{array}$ & $\begin{array}{l}\text { History of } \\
\text { mental health } \\
\text { conditions } \\
\text { HR }(95 \% \mathrm{Cl})\end{array}$ & $\begin{array}{c}\text { Self-harm } \times \\
\text { mental health } \\
\text { history } \\
\text { HR }(95 \% \mathrm{CI})\end{array}$ \\
\hline $\begin{array}{l}\text { Readmissions to ED or } \\
\text { hospital for self-harm }\end{array}$ & $365(4.7)$ & $1144(28.3)$ & $272(9.0)$ & $482(29.8)$ & $6.85(6.11-7.69)$ & $1.92(1.64-2.24)$ & $7.17(6.25-8.34)$ \\
\hline Overall mortality & $22(0.3)$ & $49(1.2)$ & $12(0.4)$ & $9(0.6)$ & $4.26(2.57-7.05)$ & $1.38(0.69-2.79)$ & $1.94(0.88-4.25)$ \\
\hline \multirow[t]{2}{*}{ Suicides } & $6(0.1)$ & $36(0.9)$ & $\leq 5$ & $6(0.4)$ & $11.48(4.79-27.5)$ & $1.69(0.48-5.98)$ & $4.76(1.51-15.00)$ \\
\hline & Mean \pm SD & Mean \pm SD & Mean \pm SD & Mean \pm SD & $p$ value & $p$ value & $p$ value \\
\hline $\begin{array}{l}\text { Lower-bound estimates of } \\
5 \text {-year health care costs, } \$\end{array}$ & $16079 \pm 44011$ & $30600 \pm 58891$ & $26591 \pm 72310$ & $29859 \pm 67002$ & $<0.001$ & $<0.001$ & $<0.001$ \\
\hline 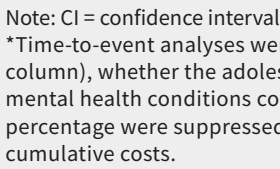 & $\begin{array}{l}\text { = emergency depa } \\
\text { Cox regressions of } \\
\mathrm{nt} \text { had a mental he } \\
\mathrm{nn}) \text {, and the intera } \\
\text { prevent reidentifi }\end{array}$ & $\begin{array}{l}\text { tment, } \mathrm{HR}=\text { hazard } \\
\text { le time to the outc } \\
\text { lth code associate } \\
\text { tion between thos } \\
\text { ation of patients. T }\end{array}$ & $\begin{array}{l}\text { me regressed on w } \\
\text { with the index em } \\
\text { narkers (self-harm } \\
\text { e bottom row of th }\end{array}$ & $\begin{array}{l}\text { ther the adolescer } \\
\text { sency department } \\
\text { mental health hist } \\
\text { table reports a } 2 \times\end{array}$ & $\begin{array}{l}\text { had a self-harm eme } \\
\text { sit or any other med } \\
\text { y column). In the ce } \\
\text { inalysis of variance }\end{array}$ & $\begin{array}{l}\text { ency department } \\
\text { I service in the las } \\
\text { ith " } \leq 5 \text {," the actu } \\
\text { the logs of the lon }\end{array}$ & $\begin{array}{l}\text { (self-harm } \\
\text { our (history of } \\
\text { ount and } \\
\text { bound 5-year }\end{array}$ \\
\hline
\end{tabular}

suicide than propensity-matched controls who did not present with self-harm. Adolescents who presented with self-harm were almost 5 times more likely to have repeat emergency department visits or hospital admissions related to self-harm, with about 1 in 3 having a repeat admission. Moreover, adolescents with self-harm had a difference in health care costs that was more than $\$ 11000$ higher (lower-bound estimate) than that of controls. Our findings are consistent with previous research $\mathrm{h}^{3-7,26}$ and show that over and above an elevated suicide risk, having an emergency department visit related to self-harm is a predictor for recurrent visits to the emergency department and greater use of health services.

Although having an emergency department visit related to self-harm was associated with a high relative risk of mortality or suicide, the positive predictive values of self-harm for these outcomes were $\leq 1 \%$. The high relative risk of suicide tells us that it is several times more common among adolescents with visits related to self-harm than for control patients. The positive predictive value of a self-harm-related visit is low because suicides are also uncommon among these adolescents. Therefore, predicting these outcomes remains challenging. ${ }^{27-29}$ The increasing prevalence among adolescents of visits related to self-harm in the emergency department setting combined with the low positive predictive value of self-harm for suicide means that deploying intensive suicide prevention efforts for all visits related to self-harm would be resource intensive ${ }^{30}$ yet prevent few suicides.

However, almost 1 in 3 adolescents with visits related to self-harm were later readmitted to a hospital or emergency department, and their clinical trajectory was more expensive than that of their matched control patients. Moreover, among adolescents who presented after self-harm, and who later had recurrent admissions for self-harm, serious and complex mental conditions were common, most prominently anxiety and mood disorders, as well as substance abuse issues, and concussion or traumatic brain injury.

These findings suggest 2 directions for future research. First, the positive predictive value of a visit after self-harm for future readmissions after self-harm, in addition to the findings that mental health and other conditions also predict readmissions, suggest that it may be possible to develop an algorithm that could accurately predict the risk of readmission. Second, our results suggest that adolescents who present at the emergency department after self-harm would benefit from assessment for mental health or substance misuse disorders. If adolescents presenting with self-harm have mental health or substance misuse issues, they should be connected to evidence-based community services for treatment. However, further research is needed on better methods to deliver mental health assessments in the emergency department setting ${ }^{31}$ as well as developing care pathways connecting the emergency department with appropriate community mental health services. ${ }^{32}$

\section{Limitations}

The matched groups were not balanced on suicidal ideation and our findings should not be interpreted as speaking to the effects of self-harm on suicidality. As in any observational study, the groups may also have differed on unmeasured variables, leading to confounding of the results. This study used administrative data and is subject to weaknesses of such data, including the lack of validation of many specific mental health or other clinical codes. ${ }^{18,33-38}$ In Appendix 1, we argue it is likely that ICD-10 codes 
Table 5: Variables associated with a self-harm readmission to emergency department or hospital for a youth with a self-harm index visit to the emergency department*

Variable

\section{Demographic covariates}

Age, $y r$, mean \pm SD

Sex, female

Neighbourhood income quintile

$$
1
$$

2

3

4

5

Rural

Mental health and substance abuse covariates

Alcohol abuse

Anxiety-neurotic disorders

Behavioural and emotional disorders

Behavioural syndromes associated with physiologic disturbances

Bipolar disorder or manic episode

Disorders of personality and behaviour

Disorders of psychological development

Eating disorders

Intellectual disability

Mood disorders other than bipolar or mania

Organic mental disorders

Other mental health disorders

Reaction to severe stress, and adjustment disorders

Schizophrenia

Substance abuse (nonalcohol)

Suicidal ideation

\section{Clinical covariates}

Acne

Asthma

Cancers

Concussion or traumatic brain injury

Congenital heart disease

Cystic fibrosis

Diabetes mellitus

Down syndrome

Eczema

Epilepsy

Inflamed bowel

Inflammatory polyarthropathies

Migraine

Neuromuscular conditions

Obesity

Psoriasis

Sickle cell anemia

Spina bifida

\section{History of self-harm}

Self-injury

Self-poisoning
No. $(\%) \dagger$ of adolescents

with no self-harm

readmissions

$n=4035$

$15.56 \pm 1.23$

3107 (77.0)

$888(22.0)$

751 (18.6)

$808(20.0)$

856 (21.2)

732 (18.1)

$593(14.7)$

259 (6.4)

2295 (56.9)

1226 (30.4)

$30(0.7)$

$404(10.0)$

$219(5.4)$

$201(5.0)$

$91(2.3)$

$18(0.4)$

1396 (34.6)

$33(0.8)$

$27(0.7)$

$826(20.5)$

138 (3.4)

$351(8.7)$

520 (12.9)

567 (14.1)

555 (13.8)

$24(0.6)$

$836(20.7)$

$24(0.6)$

$\leq 5$

$46(1.1)$

$9(0.2)$

$906(22.5)$

$56(1.4)$

$24(0.6)$

$24(0.6)$

$274(6.8)$

$8(0.2)$

134 (3.3)

$21(0.5)$

$\leq 5$

$\leq 5$

$47(1.2)$

134 (3.3)
No. $(\%) \dagger$ of adolescents

$\geq 1$ self-harm

readmissions

$n=1626$

Total

$n=5661$

$p$ value

$15.29 \pm 1.31$

$1337(82.2)$

$15.48 \pm 1.26$

4444 (78.5)

$0.21<0.001$

337 (20.7)

310 (19.1)

341 (21.0)

307 (18.9)

331 (20.4)

294 (18.1)

$1225(21.6)$

0.13

$<0.001$

1061 (18.7)

1149 (20.3)

1163 (20.5)

$1063(18.8)$

0.03

0.107

154 (9.5)

$1159(71.3)$

$715(44.0)$

$19(1.2)$

$260(16.0)$

$227(14.0)$

154 (9.5)

$75(4.6)$

$19(1.2)$

$787(48.4)$

$9(0.6)$

21 (1.3)

557 (34.3)

101 (6.2)

199 (12.2)

$449(27.6)$

887 (15.7)

0.01

0.02

0.06

0.06

0.09

0.002

$413(7.3) \quad 0.11<0.001$

$3454(61.0) \quad 0.30<0.001$

$1941(34.3) \quad 0.28<0.001$

$49(0.9) \quad 0.04 \quad 0.118$

$664(11.7) \quad 0.18<0.001$

$446(7.9) \quad 0.29<0.001$

$355(6.3) \quad 0.17<0.001$

$166(2.9) \quad 0.13<0.001$

$37(0.7) \quad 0.08 \quad 0.002$

$2183(38.6) \quad 0.28<0.001$

$\begin{array}{lll}42(0.7) & 0.03 & 0.294\end{array}$

$\begin{array}{lll}48(0.8) & 0.06 & 0.021\end{array}$

$1383(24.4) \quad 0.31<0.001$

$239(4.2) \quad 0.13<0.001$

$550(9.7) \quad 0.12<0.001$

$969(17.1) \quad 0.37<0.001$

$218(13.4)$

$242(14.9)$

$9(0.6)$

$398(24.5)$

$10(0.6)$

$\leq 5$

$38(2.3)$

$\leq 5$

$380(23.4)$

$51(3.1)$

$11(0.7)$

$9(0.6)$

$126(7.7)$

$6(0.4)$

$68(4.2)$

$14(0.9)$

$\leq 5$

$\leq 5$

785 (13.9)

0.02

797 (14.1)

$33(0.6)$

$1234(21.8)$

$34(0.6)$

$\leq 5$

$84(1.5)$

$14(0.2)$

1286 (22.7)

107 (1.9)

$35(0.6)$

$33(0.6)$

$400(7.1)$

$14(0.2)$

202 (3.6)

$35(0.6)$

$6(0.1)$

$\leq 5$

$62(3.8)$

$102(6.3)$

109 (1.9)

236 (4.2)

0.03

0.01

0.09

0.00

0.04

0.09

0.02

0.02

0.12

0.01

0.01

0.04

0.03

0.05

0.04

0.02

0.01

0.525

0.269

0.854

0.002

0.929

0.146

$<0.001$

0.563

0.456

$<0.001$

0.723

0.854

0.203

0.242

0.114

0.139

0.514

0.86
Note: $D=$ standardized group difference, $E D=$ emergency department, $S D=$ standard deviation.

"The $p$ value is the statistical significance of the covariate in a logistic regression predicting the occurrence of a self-harm readmission during the 5 years after the index visit. †Unless stated otherwise. 
for self-harm and mental health have high specificity but lower sensitivity, meaning that both are underestimated in these data. Cases of self-harm that are missed and appear in the control group would mean that the estimated differences in outcomes underestimate the true differences.

As noted, our estimates of the medical costs for adolescents were lower bounds on these costs. However, adolescents who selfharmed likely also incurred social costs, including poorer academic performance, involvement with juvenile justice and reduced adult earnings. ${ }^{13}$ Thus, the real costs of caring for adolescents who present to the emergency department with self-harm are likely substantially larger than reported here. Moreover, emergency department health administrative records may miss many adolescents with mental health conditions. Some emergency departments are unable to carry out mental health assessments. In addition, National Ambulatory Care Reporting System records require only that the main problem leading to the visit be recorded, so diagnoses relating to mental health are sometimes missed when the patient has an emergent medical issue. ${ }^{39}$ Therefore, our results may understate the associations between mental health conditions and 5-year adverse outcomes. Finally, adolescents in Ontario may differ from those in other jurisdictions and the exposures affecting adolescents today may have changed since 2011-2013.

\section{Conclusion}

An adolescent emergency department visit related to intentional self-harm increases risk of repeated self-harm and suicide, as well as increased health costs over the next 5 years. In light of the increasing rates of self-harm emergency department visits for adolescents, further research is needed on the social determinants of self-harm and could focus on developing algorithms and interventions that can identify and help the adolescents at highest risk of recurrent self-harm.

\section{References}

1. Posner K, Brodsky B, Yershova K, et al. The classification of suicidal behavior. In: Nock M, editor. The Oxford Handbook of Suicide and Self-Injury. Oxford (UK): Oxford University Press; 2014: 7-22.

2. Herbert A, Gilbert R, González-Izquierdo A, et al. 10-y risks of death and emergency re-admission in adolescents hospitalised with violent, drug- or alcoholrelated, or self-inflicted injury: a population-based cohort study. PLoS Med 2015;12:e1001931.

3. Cooper J, Kapur N, Webb R, et al. Suicide after deliberate self-harm: a 4-year cohort study. Am J Psychiatry 2005;162:297-303.

4. Finkelstein Y, Macdonald EM, Hollands S, et al.; Canadian Drug Safety and Effectiveness Research Network (CDSERN). Long-term outcomes following self-poisoning in adolescents: a population-based cohort study. Lancet Psychiatry 2015;2:532-9.

5. Hawton K, Bergen H, Kapur N, et al. Repetition of self-harm and suicide following self-harm in children and adolescents: findings from the Multicentre Study of Self-harm in England. J Child Psychol Psychiatry 2012;53:1212-9.

6. Hawton K, Bergen $\mathrm{H}$, Cooper J, et al. Suicide following self-harm: findings from the Multicentre Study of self-harm in England, 2000-2012. J Affect Disord 2015;175:147-51.

7. Olfson M, Wall M, Wang S, et al. Suicide after deliberate self-harm in adolescents and young adults. Pediatrics 2018;141:e20173517. doi:10.1542/peds.2017-3517.

8. Herbert A, Gilbert R, González-Izquierdo A, et al. Violence, self-harm and drug or alcohol misuse in adolescents admitted to hospitals in England for injury: a retrospective cohort study. BMJ Open 2015;5:e006079.
9. Bennardi M, McMahon E, Corcoran P, et al. Risk of repeated self-harm and associated factors in children, adolescents and young adults. BMC Psychiatry 2016;16:421.

10. Hawton K, Harriss L. Deliberate self-harm in young people: characteristics and subsequent mortality in a 20 -year cohort of patients presenting to hospital. $J$ Clin Psychiatry 2007;68:1574-83.

11. Mars B, Heron J, Crane C, et al. Clinical and social outcomes of adolescent self harm: population based birth cohort study. BMJ 2014;349:g5954.

12. Moran P, Coffey $\mathrm{C}$, Romaniuk $\mathrm{H}$, et al. Substance use in adulthood following adolescent self-harm: a population-based cohort study. Acta Psychiatr Scand 2015;131:61-8

13. Borschmann R, Becker D, Coffey C, et al. 20-year outcomes in adolescents who self-harm: a population-based cohort study. Lancet Child Adolesc Health 2017;1:195-202.

14. Tsiachristas A, McDaid D, Casey D, et al. General hospital costs in England of medical and psychiatric care for patients who self-harm: a retrospective analysis. Lancet Psychiatry 2017;4:759-67.

15. Gardner W, Pajer K, Cloutier P, et al. Changing rates of self-harm and mental disorders by sex in youths presenting to Ontario emergency departments: repeated cross-sectional study. Can J Psychiatry 2019 June 11 [Epub ahead of print]. doi:10.1177/0706743719854070.

16. Twenge JM. Why increases in adolescent depression may be linked to the technological environment. Curr Opin Psychol 2019;32:89-94.

17. International Statistical Classification of Diseases and Related Health Problems 10th Revision (ICD-10 Version: 2016). Geneva: World Health Organization; 2016.

18. Gibson D, Richards H, Chapman A. The National Ambulatory Care Reporting System: factors that affect the quality of its emergency data. International Journal of Information Quality 2008;2:97-114. doi:10.1504/IJIQ.2008.022958.

19. Gatov E, Kurdyak P, Sinyor M, et al. Comparison of vital statistics definitions of suicide against a coroner reference standard: a population-based linkage study. Can J Psychiatry 2018;63:152-60.

20. de Oliveira C, Cheng J, Vigod S, et al. Patients with high mental health costs incur over 30 percent more costs than other high-cost patients. Health Aff (Millwood) 2016;35:36-43.

21. Singhal A, Ross J, Seminog O, et al. Risk of self-harm and suicide in people with specific psychiatric and physical disorders: comparisons between disorders using English national record linkage. J R Soc Med 2014;107:194-204.

22. Stuart EA. Matching methods for causal inference: a review and a look forward. Stat Sci 2010;25:1-21.

23. Austin PC. The performance of different propensity-score methods for estimating differences in proportions (risk differences or absolute risk reductions) in observational studies. Stat Med 2010;29:2137-48.

24. Austin PC. A comparison of 12 algorithms for matching on the propensity score. Stat Med 2014;33:1057-69.

25. Cohen J. Statistical power analysis for the behavioral sciences. New York: Academic Press; 1977.

26. Chan MK, Bhatti $\mathrm{H}$, Meader $\mathrm{N}$, et al. Predicting suicide following self-harm: systematic review of risk factors and risk scales. Br J Psychiatry 2016;209:277-83.

27. Franklin JC, Ribeiro JD, Fox KR, et al. Risk factors for suicidal thoughts and behaviors: a meta-analysis of 50 years of research. Psychol Bull 2017;143:187-232.

28. Belsher BE, Smolenski DJ, Pruitt LD, et al. Prediction models for suicide attempts and deaths: a systematic review and simulation. JAMA Psychiatry 2019;76:642-51.

29. Roberts LW, Berk MS, Lane-McKinley K. Ethical considerations in research on suicide prediction: necessity as the mother of invention. JAMA Psychiatry 2019 July 3 [Epub ahead of print]. doi:10.1001/jamapsychiatry.2019.1228.

30. Brent DA, Oquendo MA, Reynolds CF III. Caring for suicidal patients. JAMA Psychiatry 2019 June 12 [Epub ahead of print]. doi:10.1001/jamapsychiatry.2019.0927.

31. Southard EP, Neufeld JD, Laws S. Telemental health evaluations enhance access and efficiency in a critical access hospital emergency department. Telemed J E Health 2014;20:664-8.

32. Jabbour M, Reid S, Polihronis C, et al. Improving mental health care transitions for children and youth: a protocol to implement and evaluate an emergency department clinical pathway. Implement Sci 2016;11:90. 
33. Benchimol El, Smeeth L, Guttmann A, et al.; RECORD Working Committee. The REporting of studies Conducted using Observational Routinely-collected health Data (RECORD) statement. PLoS Med 2015;12:e1001885.

34. Rhodes AE, Links PS, Streiner DL, et al. Do hospital E-codes consistently capture suicidal behaviour? Chronic Dis Can 2002;23:139-45.

35. Steele LS, Glazier RH, Lin E, et al. Using administrative data to measure ambulatory mental health service provision in primary care. Med Care 2004;42:960-5.

36. Bethell J, Rhodes AE. Identifying deliberate self-harm in emergency department data. Health Rep 2009;20:35-42.
37. Clements C, Turnbull P, Hawton K, et al. Rates of self-harm presenting to general hospitals: a comparison of data from the Multicentre Study of Self-Harm in England and Hospital Episode Statistics. BMJ Open 2016;6:e009749.

38. Randall JR, Roos LL, Lix LM, et al. Emergency department and inpatient coding for self-harm and suicide attempts: validation using clinician assessment data. Int J Methods Psychiatr Res 2017;26:e1559.

39. NACRS data elements 2018-2019. Ottawa: Canadian Institute for Health Information.

\begin{abstract}
Competing interests: William Gardner reports receiving grants from the Canadian Institutes of Health Research and research contracts from the Public Health Agency of Canada and the US Centers for Disease Control. Dr. Gardner is also the CHEO and University of Ottawa Senior Research Chair in Child and Adolescent Psychiatry. Ian Colman is a Canada Research Chair in mental health epidemiology. Roger Zemek reports receiving competitively funded research grants from the Canadian Institutes of Health Research, Ontario Neurotrauma Foundation, Physician Services Incorporated Foundation, CHEO Foundation, Ontario Brain Institute, the Ontario SPOR Support Unit and the National Football League. Dr. Zemek is also the Clinical Research Chair in Pediatric Concussion at University of Ottawa. No other competing interests were declared.
\end{abstract}

This article has been peer reviewed.

Affiliations: School of Epidemiology \& Public Health (Gardner, Currie, Colman), University of Ottawa; Children's Hospital of Eastern Ontario Research Institute (Gardner, Cloutier, Zemek, Cappelli); Departments of Psychiatry (Pajer) and Pediatrics (Zemek), University of Ottawa; The Ottawa Hospital Research Institute (Hatcher, Lima); ICES uOttawa (Lima), Ottawa, Ont.
Contributors: William Gardner, Kathleen Pajer, Paula Cloutier, Lisa Currie, Ian Colman, Roger Zemek, Simon Hatcher and Mario Cappelli contributed to the conception and design of the work. William Gardner, Kathleen Pajer, Paula Cloutier and Lisa Currie contributed to the acquisition of the data. William Gardner and Isac Lima contributed to the analysis and interpretation of the data. William Gardner, Kathleen Pajer, Ian Colman, Roger Zemek and Simon Hatcher contributed to the drafting of the manuscript. William Gardner and Kathleen Pajer contributed to securing the funding for the research. All authors contributed to the revision of critical content in the manuscript, gave final approval of the version to be published and agreed to be accountable for all aspects of the work.

Funding: This research was funded by a grant from the Scotiabank Foundation to William Gardner and Kathleen Pajer. The researchers are wholly independent from the funders. The funders had no role in the design and conduct of the study; the collection, management, analysis and interpretation of the data; the preparation, review or approval of the manuscript; or the decision to submit the manuscript for publication.
Data sharing: These data were accessed through ICES and are not available from the authors. Researchers interested in analyzing these data are encouraged to contact ICES (www.ices.on.ca) to learn how the data may be accessed.

Acknowledgements: The authors thank Daniel Rodriguez Duque for assistance with the analysis and Paul Kurdyak for serving as the ICES Scientist on this project.

Disclaimer: This study was supported by ICES, which is funded by an annual grant from the Ontario Ministry of Health and Long-Term Care (MOHLTC). The opinions, results and conclusions reported in this paper are those of the authors and are independent from the funding sources. No endorsement by ICES or the MOHLTC is intended or should be inferred. Parts of this material are based on data and/or information compiled and provided by the Canadian Institute of Health Information (CIHI). However, the analyses, conclusions, opinions and statements expressed in the material are those of the author(s), and not necessarily those of $\mathrm{CIHI}$.

Accepted: Sept. 23, 2019

Correspondence to: William Gardner, wgardner@cheo.on.ca 